\title{
Disparities in survival for right-sided vs. left-sided colon cancers in young patients: a study based on the Surveillance, Epidemiology, and End Results database (1990-2014)
}

This article was published in the following Dove Press journal:

Cancer Management and Research

\author{
Yaqi Wang ${ }^{1,2, *}$ \\ Lifeng Yang ${ }^{1,2, *}$ \\ Menglong Zhou ${ }^{1,2}$ \\ Lijun Shen ${ }^{1,2}$ \\ Jing Zhang ${ }^{1,2}$ \\ Weijuan Deng ${ }^{1,2}$ \\ Liping Liang ${ }^{1,2}$ \\ Ran $\mathrm{Hu}^{1,2}$ \\ Wang Yang ${ }^{1,2}$ \\ Ye Yao ${ }^{1,2}$ \\ Zhen Zhang ${ }^{1,2}$
}

'Department of Radiation Oncology, Fudan University Shanghai Cancer Center, Shanghai 200032, People's Republic of China; ${ }^{2}$ Department of Oncology, Shanghai Medical College, Fudan University, Shanghai 200032 ,

People's Republic of China

*These authors contributed equally to this work

Correspondence: Zhen Zhang Department of Radiation Oncology, Fudan University Shanghai Cancer Center, 270 Dong An Road, Shanghai 200032, People's Republic of China Tel +862I64I75590

Email zhen_zhang@fudan.edu.cn
Purpose: To investigate whether young patients exhibit different characteristics and survival according to tumor location and stage using data from the Surveillance, Epidemiology, and End Results (SEER) database.

Patients and methods: Young patients (20-49 years old) with stage I-III colon cancers were identified from the SEER program from 1990 to 2014. Kaplan-Meier survival analysis and Cox proportional hazards regression were used to analyze the data. Subset analyses were also done among different age and stage subgroups.

Results: Of 8197 patients, 3709 (45.2\%) had right-sided colon cancers (RCCs). Patients with RCCs were more likely to be male, to be younger, and to have more poorly differentiated and more advanced tumors. The Kaplan-Meier survival curves and univariate survival models revealed that left-sided colon cancers (LCCs) had lower mortality for all stages combined and stage III, but higher mortality for stage II, compared with right-sided tumors. However, multivariate Cox regression models showed no significant survival differences by location for all patients (adjusted hazard ratio [HR], 0.95; 95\% confidence interval [CI], 0.86-1.05; $P=0.34$ ) or for stage I (adjusted HR, 1.47; 95\% CI, 0.82-2.63; $P=0.20$ ). Stage II left-sided cancers had higher mortality (adjusted HR, 1.24; 95\% CI, 1.00-1.54; $P=0.048$ ), whereas stage III leftsided cancers had lower mortality (adjusted HR, 0.86 ; 95\% CI, $0.77-0.97 ; P=0.01$ ). For 20 - to 39 -year-old patients, a significant difference was only found in stage II disease, with a higher mortality for left-sided tumors (adjusted HR, 1.82; 95\% CI, 1.12-2.97; $P=0.02$ ). However, for 40- to 49-year-old patients, a significant difference was only found in stage III disease, with a lower mortality for left-sided tumors (adjusted HR, 0.83; 95\% CI, 0.72-0.95; $P=0.008$ ).

Conclusion: In patients younger than 50 years, there were no significant differences in mortality between RCCs and LCCs for all stages combined after adjusting for multiple clinicopathological features. However, RCCs had lower mortality in stage II (especially in 20- to 39-year-old patients) and higher mortality in stage III (especially in 40- to 49-year-old patients).

Keywords: young patients, survival, right-sided colon cancers, left-sided colon cancers, stages, SEER

\section{Introduction}

Colorectal cancer (CRC) is the second leading cause of cancer deaths in the USA. ${ }^{1}$ Many studies have found that left-sided colon cancers (LCCs) and right-sided colon cancers (RCCs) are two distinct cancers. ${ }^{2}$ The association between cancer location and mortality remains controversial. Many studies have shown that patients with RCCs 
have shorter survival than do patients with LCCs. ${ }^{3-6}$ However, other researchers have shown that there is no significant survival difference according to tumor location. ${ }^{7,8}$ Recently, an analysis of the results of six randomized trials (including CRYSTAL, FIRE-3, CALGB 80405, etc) showed that metastatic RCCs and LCCs seem to have different survival outcomes with different targeted agents. ${ }^{9}$ Hopefully, these cancers will be treated with different approaches in the future.

The incidence of CRC has been declining rapidly over the past several decades. However, the incidence in young adults is increasing. ${ }^{10,11}$ Clinicopathological and survival disparities between young and elderly patients remain controversial. Most studies have focused on elderly patients. The survival differences between LCCs and RCCs among young patients are not clear. Thus, we compared the pathological characteristics and survival outcomes between LCCs and RCCs among young patients (20-49 years old) to investigate whether young patients exhibit different survival and characteristics according to tumor location and, more specifically, to determine if this relationship is consistent across different tumor stages.

\section{Patients and methods}

\section{Data source}

We conducted a population-based retrospective cohort study of young patients (20-49 years old) diagnosed with LCCs and RCCs from the Surveillance, Epidemiology, and End Results (SEER) program registries, a nationally representative collection of population-based registries of all incident cancers from Atlanta, Connecticut, Detroit, Hawaii, Iowa, New Mexico, San Francisco-Oakland, Seattle-Puget Sound, and Utah in the USA. The SEER registry provides high-quality data on cancer incidence, clinicopathological features, and mortality. We obtained permission to access the research data files with the reference number 11488-Nov2016. This permission did not include interaction with human subjects or use of personally identifying information and did not require informed consent.

\section{Patient selection}

Young patients (20-49 years old) who were diagnosed with LCCs or RCCs in the SEER database from 1990 to 2014 were included in the study. The site codes (ICD-O-3) used included the following: right colon-C18.0 and C18.2-C18.4, corresponding to the cecum, ascending colon, hepatic flexure, and transverse colon, respectively; left colon-C18.5-C18.7, corresponding to splenic flexure, descending colon, and sigmoid colon, respectively. Large intestine NOS (C18.8-C18.9, C26.0) were excluded from the study because the locations of their cancers were not clear. Only patients with one primary adenocarcinoma (microscopically confirmed) were included, and the patients who were diagnosed with another malignancy 1 year before or after the date of colon cancer diagnosis were excluded. Adenocarcinoma referred to SEER histology codes $8010,8140-8147,8210-8211,8220-8221,8260-8263$, 8480-8481, and 8490. In addition, patients with unknown stages and survival months were excluded. Cancer-specific survival (CSS) was acquired from the database. The date of the final analysis was October 10, 2017.

\section{Statistical analysis}

Data for all categorical variables were summarized as frequencies, and data for all continuous variables were presented as medians and ranges. The chi-square test was used to compare differences in the distributions and proportions of the demographic and clinicopathological variables by tumor location. Survival curves were calculated using the KaplanMeier method, and survival functions were compared using the log-rank test. Unadjusted and adjusted Cox proportional hazards regression analyses were used to estimate the association between tumor location and outcomes (CSS) and to obtain the corresponding hazard ratios (HRs) and 95\% confidence intervals (CIs) for the different predictors. The adjusted Cox regression models included year of diagnosis, age group, sex, race, histological subtype, tumor grade, American Joint Committee on Cancer (AJCC) TNM stage, and marriage status. Differences were considered statistically significant for $P$-values $<0.05$. All statistical analyses were performed using SPSS version 22.0 (IBM Corporation, Armonk, NY, USA).

\section{Results}

\section{Patient characteristics}

A total of 8197 young patients (20-49 years old) were finally included in the study. The characteristics of the patient cohort are shown in Table 1. Among the 8197 patients, 52.1\% (4273 of 8197 ) were male and $47.9 \%$ (3924 of 8197) were female. The cases were most commonly diagnosed between the ages of 40 and 49 years (74.3\% [6092 of 8197]). Poor differentiation was observed in $17.6 \%$ (1442 of 8197 ) of the tumors. The majority of cases were diagnosed as stage III colon cancers (46.0\% [3772 of 8197]), which was followed by stage II colon cancers (33.3\% [2726 of 8197]). More than 12 lymph nodes (LNs) were examined in 70.1\% (5750 of 8197) of patients.

The cohort included 45.2\% (3709 of 8197) RCCs and $54.8 \%$ (4488 of 8197) LCCs. Compared with LCCs, RCC cases were more likely to be male (56.1\% [2082 of 3709] 
Table I Demographic and clinicopathological features of patients with stage I-III colon cancers

\begin{tabular}{|c|c|c|c|c|}
\hline Characteristic & $\begin{array}{l}\text { All } \\
(N=8 \mid 97)\end{array}$ & $\begin{array}{l}\text { RCC } \\
(N=3709)\end{array}$ & $\begin{array}{l}\text { LCC } \\
(\mathrm{N}=4488)\end{array}$ & $P$ \\
\hline \multicolumn{5}{|l|}{ Age group } \\
\hline $20-29$ & 402 (4.9) & $203(5.5)$ & $199(4.4)$ & 0.001 \\
\hline $30-39$ & $1703(20.8)$ & $823(22.2)$ & $880(19.6)$ & \\
\hline $40-49$ & $6092(74.3)$ & $2683(72.3)$ & 3409 (76.0) & \\
\hline \multicolumn{5}{|l|}{ Sex } \\
\hline Male & $4273(52.1)$ & $2082(56.1)$ & $2191(48.8)$ & $<0.001$ \\
\hline Female & 3924 (47.9) & 1627 (43.9) & $2297(51.2)$ & \\
\hline \multicolumn{5}{|l|}{ Race } \\
\hline White & 5889 (71.8) & 2639 (7I.2) & $3250(72.4)$ & $<0.001$ \\
\hline Black & $1269(15.5)$ & $681(18.4)$ & $588(13.1)$ & \\
\hline Other & $992(12.1)$ & $371(10.0)$ & $621(13.8)$ & \\
\hline Unknown & $47(0.6)$ & $18(0.5)$ & $29(0.6)$ & \\
\hline \multicolumn{5}{|l|}{ Marital status } \\
\hline Married & $5015(61.2)$ & $2237(60.3)$ & $2778(61.9)$ & 0.34 \\
\hline Widowed & $83(1.0)$ & $37(1.0)$ & $46(1.0)$ & \\
\hline $\begin{array}{l}\text { Single, separated, } \\
\text { or divorced }\end{array}$ & 2775 (33.9) & $1294(34.9)$ & $|48|(33.0)$ & \\
\hline Unknown & $324(4.0)$ & $|4|$ (3.8) & $183(4.1)$ & \\
\hline \multicolumn{5}{|l|}{ AJCC stage } \\
\hline I & 1699 (20.7) & $530(14.3)$ & $1169(26.0)$ & $<0.001$ \\
\hline II & $2726(33.3)$ & $1450(39.1)$ & $1276(28.4)$ & \\
\hline III & $3772(46.0)$ & $1729(46.6)$ & $2043(45.5)$ & \\
\hline \multicolumn{5}{|l|}{ Histological type } \\
\hline Adenocarcinoma & $7102(86.6)$ & $2978(80.3)$ & $4 \mid 24$ (91.9) & $<0.001$ \\
\hline $\begin{array}{l}\text { Mucinous } \\
\text { adenocarcinoma }\end{array}$ & $968(11.8)$ & $653(17.6)$ & $315(7.0)$ & \\
\hline $\begin{array}{l}\text { Signet ring cell } \\
\text { carcinoma }\end{array}$ & $127(1.5)$ & $78(2.1)$ & $49(1.1)$ & \\
\hline \multicolumn{5}{|l|}{ Grade } \\
\hline $\begin{array}{l}\text { Well } \\
\text { differentiated }\end{array}$ & $712(8.7)$ & $277(7.5)$ & $435(9.7)$ & $<0.001$ \\
\hline $\begin{array}{l}\text { Moderately } \\
\text { differentiated }\end{array}$ & $5506(67.2)$ & $2342(63.1)$ & $3164(70.5)$ & \\
\hline $\begin{array}{l}\text { Poorly } \\
\text { differentiated }\end{array}$ & $1442(17.6)$ & $843(22.7)$ & $599(13.3)$ & \\
\hline Undifferentiated & $116(1.4)$ & $68(1.8)$ & $48(I . I)$ & \\
\hline Unknown & $421(5.1)$ & $179(4.8)$ & $242(5.4)$ & \\
\hline \multicolumn{5}{|l|}{ No. of LNs examined } \\
\hline $0-11$ & 2447 (29.9) & $740(20.0)$ & $1707(38.0)$ & $<0.001$ \\
\hline$\geq 12$ & $5750(70.1)$ & $2969(80.0)$ & $2781(62.0)$ & \\
\hline \multicolumn{5}{|l|}{ Year of diagnosis } \\
\hline $1990-1994$ & 1267 (I5.5) & $697(16.4)$ & $660(14.7)$ & 0.12 \\
\hline $1995-1999$ & $1456(17.8)$ & $672(18.1)$ & $784(17.5)$ & \\
\hline 2000-2004 & $1760(21.5)$ & $803(21.7)$ & $957(21.3)$ & \\
\hline 2005-2009 & $1805(22.0)$ & $789(21.3)$ & $1016(22.6)$ & \\
\hline $2010-2014$ & $1909(23.3)$ & $838(22.6)$ & I07| (23.9) & \\
\hline
\end{tabular}

Note: Data are presented as $\mathrm{n}(\%)$.

Abbreviations: RCC, right-sided colon cancer; LCC, left-sided colon cancer; AJCC, American Joint Committee on Cancer; LNs, lymph nodes.

vs. $48.8 \%$ [ 2191 of 4488 ], $P<0.001)$ and younger $(20-39$ years old: $27.7 \%$ [1026 of 3709 ] vs. $24.0 \%$ [1079 of 4488], $P<0.001)$. There were more Black patients among RCC cases (18.4\% [681 of 3709] vs. $13.1 \%$ [588 of 4488$], P<0.001)$ and more Asian and other patients among LCC cases $(10.0 \%$ [ 371 of 3709 ] vs. $13.8 \%$ [621 of 4488], $P<0.001$ ). RCC cases exhibited a lower frequency of stage I tumors $(14.3 \%$ [530 of 3709] vs. $26.0 \%$ [1169 of 4488]), a higher frequency of stage II tumors (39.1\% [ 1450 of 3709 ] vs. $28.4 \%$ [1276 of $4488]$ ), and a slightly higher frequency of stage III tumors (46.6\% [1729 of 3709] vs. $45.5 \%$ [2043 of 4488]). Compared with LCCs, RCCs had a greater proportion of mucinous adenocarcinomas or signet ring cell carcinomas (19.7\% [731 of 3709] vs. $8.1 \%$ [364 of 4488], $P<0.001)$ and more poorly differentiated tumors $(22.7 \%$ [ 843 of 3709$]$ vs. $13.3 \%$ [599 of 4488], $P<0.001)$. Moreover, RCC cases exhibited a higher frequency of more than $12 \mathrm{LNs}$ examined $(80 \%$ [2969 of 3709] vs. $62.0 \%$ [ 2781 of 4488 ], $P<0.001$ ). In addition, although the incidences of both LCCs and RCCs were increasing over the past 25 years (1990-2014), there was no significant difference in incidence between LCCs and $\operatorname{RCCs}(P=0.12)$.

The patients' characteristics by stage and location are listed in Table 2. The distributions of race, marital status, histological type, grade, and the number of LNs examined are the same across stage I, stage II, and stage III groups. Unlike stage II and III patients, stage I RCC and LCC groups have the same sex and age proportions. Interestingly, we found a significant increase of LCCs compared with RCCs among stage III patients over the years of diagnosis $(P=0.03)$.

\section{Prognostic factors of CSS in young patients}

The univariate and multivariate Cox proportional hazards regression analyses were firstly performed for all stages combined (Table 3). For all stages in the 20- to 49 -year-old patients, significant clinicopathological features of increased mortality were decreasing age, Black ethnicity, right-sided location, being single, separated, or divorced, increasing AJCC stage, being mucinous or signet ring cell carcinoma, poor differentiation, the inadequate number of $(0-11) \mathrm{LNs}$ examined, and earlier year of diagnosis. The Kaplan-Meier survival curves of LCCs vs. RCCs are shown in Figure 1A ( $P=0.002)$.

However, after adjusting for the above mentioned significant clinicopathological variables, age distribution and location were no longer the prognostic factors (age: $P=0.11$ and location: adjusted HR, $0.95 ; 95 \% \mathrm{CI}, 0.86-1.05 ; P=0.34$ ), while race, marital status, AJCC stage, histological type, grade, the number of LNs examined, and year of diagnosis were independent prognostic factors (all $P<0.001$ ). Thus, the results indicated that tumor location was not an independent 
Table 2 Demographic and clinicopathological features of patients with stage I-III colon cancers stratified by stages and location

\begin{tabular}{|c|c|c|c|c|c|c|c|c|c|}
\hline \multirow[t]{2}{*}{ Characteristic } & \multicolumn{3}{|c|}{ Stage I $(N=$ I 699) } & \multicolumn{3}{|c|}{ Stage II $(\mathrm{N}=2726)$} & \multicolumn{3}{|c|}{ Stage III $(N=3772)$} \\
\hline & RCC & LCC & $P$ & RCC & LCC & $P$ & RCC & LCC & $P$ \\
\hline \multicolumn{10}{|l|}{ Age group } \\
\hline $20-29$ & $17(3.2)$ & $36(3.1)$ & 0.31 & $75(5.2)$ & $57(4.5)$ & 0.08 & III (6.4) & $106(5.2)$ & 0.16 \\
\hline $30-39$ & $99(18.7)$ & $184(15.7)$ & & $324(22.3)$ & $246(19.3)$ & & $400(23.1)$ & $450(22.0)$ & \\
\hline $40-49$ & $414(78.1)$ & $949(81.2)$ & & $105 \mid(72.5)$ & $973(76.3)$ & & $1218(70.4)$ & 1487 (72.8) & \\
\hline \multicolumn{10}{|l|}{ Sex } \\
\hline Male & $278(52.5)$ & $583(49.9)$ & 0.32 & $833(57.4)$ & $646(50.6)$ & $<0.001$ & 971 (56.2) & $962(47.1)$ & $<0.001$ \\
\hline Female & $252(47.5)$ & $586(50.1)$ & & $617(42.6)$ & $630(49.4)$ & & $758(43.8)$ & $108 \mid(52.9)$ & \\
\hline \multicolumn{10}{|l|}{ Race } \\
\hline White & $380(71.7)$ & $902(77.2)$ & 0.001 & $1028(70.9)$ & 914 (7I.6) & 0.001 & |23| (7|.2) & 1434 (70.2) & $<0.001$ \\
\hline Black & $93(17.5)$ & $123(10.5)$ & & $276(19.0)$ & $184(14.4)$ & & $312(18.0)$ & $281(13.8)$ & \\
\hline Other & $52(9.8)$ & $128(10.9)$ & & $142(9.8)$ & $171(13.4)$ & & $177(10.2)$ & $322(15.8)$ & \\
\hline Unknown & $5(0.9)$ & $16(1.4)$ & & $4(0.3)$ & $7(0.5)$ & & $9(0.5)$ & $6(0.3)$ & \\
\hline \multicolumn{10}{|l|}{ Marital status } \\
\hline Married & $330(62.3)$ & $729(62.4)$ & 0.67 & $863(59.5)$ & $767(60.1)$ & 0.87 & $1044(60.4)$ & $2326(62.8)$ & 0.48 \\
\hline Widowed & $3(0.6)$ & $13(1.1)$ & & $14(1.0)$ & $10(0.8)$ & & $20(1.2)$ & $43(1.1)$ & \\
\hline Single, separated, or divorced & $168(31.7)$ & $356(30.5)$ & & $522(36.0)$ & $449(35.2)$ & & $604(34.9)$ & $676(33.1)$ & \\
\hline Unknown & $29(5.5)$ & $71(6.1)$ & & $51(3.5)$ & $50(3.9)$ & & $61(3.5)$ & $62(3.0)$ & \\
\hline \multicolumn{10}{|l|}{ Histological type } \\
\hline Adenocarcinoma & $484(91.3)$ & $1139(97.4)$ & $<0.001$ & II 55 (79.7) & $1156(90.6)$ & $<0.001$ & 1339 (77.4) & $1829(89.5)$ & $<0.001$ \\
\hline Mucinous adenocarcinoma & $45(8.5)$ & $28(2.4)$ & & $279(19.2)$ & $117(9.2)$ & & $329(19.0)$ & $170(8.3)$ & \\
\hline Signet ring cell carcinoma & $\mathrm{I}(0.2)$ & $2(0.2)$ & & $16(1.1)$ & $3(0.2)$ & & $6 \mathrm{I}(3.5)$ & $44(2.2)$ & \\
\hline \multicolumn{10}{|l|}{ Grade } \\
\hline Well differentiated & $92(17.4)$ & $205(17.5)$ & 0.008 & $106(7.3)$ & $105(8.2)$ & $<0.001$ & $79(4.6)$ & $125(6.1)$ & $<0.001$ \\
\hline Moderately differentiated & $333(62.8)$ & $731(62.5)$ & & $1009(69.6)$ & $992(77.7)$ & & $1000(57.8)$ & $|44|(70.5)$ & \\
\hline Poorly differentiated & $49(9.2)$ & $66(5.6)$ & & $266(18.3)$ & $138(10.8)$ & & $528(30.5)$ & $395(19.3)$ & \\
\hline Undifferentiated & $5(0.9)$ & $5(0.4)$ & & $20(1.4)$ & II (0.9) & & $43(2.5)$ & $32(1.6)$ & \\
\hline Unknown & $51(9.6)$ & $162(13.9)$ & & $49(3.4)$ & $30(2.4)$ & & $79(4.6)$ & $50(2.4)$ & \\
\hline \multicolumn{10}{|l|}{ No. of LNs examined } \\
\hline $0-11$ & $155(29.2)$ & $684(58.5)$ & $<0.001$ & $281(19.4)$ & $422(33.1)$ & $<0.001$ & $304(17.6)$ & $601(29.4)$ & $<0.001$ \\
\hline$\geq 12$ & $375(70.8)$ & $485(4 \mid .5)$ & & $1169(80.6)$ & $854(66.9)$ & & $1425(82.4)$ & $1442(70.6)$ & \\
\hline \multicolumn{10}{|l|}{ Year of diagnosis } \\
\hline $1990-1994$ & $73(13.8)$ & $146(12.5)$ & 0.28 & $245(16.9)$ & $228(17.9)$ & 0.73 & $289(16.7)$ & $286(14.0)$ & 0.03 \\
\hline $1995-1999$ & $80(15.1)$ & $200(17.1)$ & & $273(18.8)$ & $239(18.7)$ & & $319(18.4)$ & $345(16.9)$ & \\
\hline $2000-2004$ & $102(19.2)$ & $268(22.9)$ & & $339(23.4)$ & $274(21.5)$ & & $362(20.9)$ & $415(20.3)$ & \\
\hline 2005-2009 & $137(25.8)$ & $276(23.6)$ & & $285(19.7)$ & 267 (20.9) & & $367(2 \mid .2)$ & $473(23.2)$ & \\
\hline $2010-2014$ & $138(26.0)$ & $279(23.9)$ & & $308(21.2)$ & $268(21.0)$ & & $392(22.7)$ & $524(25.6)$ & \\
\hline
\end{tabular}

Note: Data are presented as $n(\%)$.

Abbreviations: RCC, right-sided colon cancer; LCC, left-sided colon cancer; LNs, lymph nodes.

prognostic factor for CSS in all 20- to 49-year-old colon cancer patients.

\section{Survival analyses by tumor stage and location}

We separated all the 20- to 49-year-old patients into three stage groups. The Kaplan-Meier survival curves (Figure 1B-D) and univariate Cox model (Table 4) revealed that the significant benefit of LCCs over RCCs only existed in the stage III group (Figure 1D; HR, 0.80; 95\% CI, 0.72-0.90; $P<0.001$ ). In the stage I group, the CSS was similar between LCC and RCC cases (Figure 1B; HR, 1.08; 95\% CI, 0.62-1.86; $P=0.79$ ). However, the RCC cases had a better CSS than did the stage II LCC cases (Figure 1C; HR, 1.36; 95\% CI, 1.11-1.66;
$P=0.003$ ), but this result was similar to the findings in stage II cases older than 50 years in some previous studies.

After adjustment for age distribution, sex, race, histological subtype, tumor grade, AJCC stage, marriage status, the number of LNs examined, and year of diagnosis (Table 4), stage II LCCs still had higher mortality than RCCs (adjusted HR, 1.24; 95\% CI, 1.00-1.54; $P=0.048$ ), and stage III LCCs still had lower mortality (adjusted HR, 0.86; 95\% CI, $0.77-0.97 ; P=0.01)$. No significant differences in mortality were observed between LCCs and RCCs in stage I (adjusted HR, $1.47 ; 95 \%$ CI, $0.82-2.63 ; P=0.20$ ). Tumor location was not the independent prognostic factor in all stages of cancers in young patients, and this conclusion was not consistent across different stage groups. 
Table 3 Univariate and multivariate survival analysis of prognostic factors in young colon cancer patients (20-49 years old)

\begin{tabular}{|c|c|c|c|c|}
\hline \multirow[t]{2}{*}{ Characteristic } & \multicolumn{2}{|c|}{ Univariate survival analysis } & \multicolumn{2}{|c|}{ Multivariate survival analysis* } \\
\hline & HR (95\% Cl) & $P$ & HR (95\% Cl) & $P$ \\
\hline \multicolumn{5}{|l|}{ Age group } \\
\hline $20-29$ & I & 0.048 & I & 0.11 \\
\hline $30-39$ & $0.76(0.6 \mathrm{I}-0.96)$ & & $0.91(0.72-1.14)$ & \\
\hline $40-49$ & $0.77(0.63-0.95)$ & & $1.03(0.84-1.28)$ & \\
\hline \multicolumn{5}{|l|}{ Sex } \\
\hline Male & I & 0.17 & I & 0.15 \\
\hline Female & $0.93(0.85-1.03)$ & & $0.93(0.84-1.03)$ & \\
\hline \multicolumn{5}{|l|}{ Race } \\
\hline White & I & $<0.001$ & I & $<0.001$ \\
\hline Black & $1.49(1.31-1.68)$ & & I.4I (I.24-I.59) & \\
\hline Other & $1.14(0.99-1.33)$ & & $1.14(0.98-1.32)$ & \\
\hline Unknown & $0.13(0.02-0.93)$ & & $0.17(0.02-1.20)$ & \\
\hline \multicolumn{5}{|l|}{ Location } \\
\hline RCC & I & 0.002 & I & 0.34 \\
\hline LCC & $0.86(0.78-0.95)$ & & $0.95(0.86-1.05)$ & \\
\hline \multicolumn{5}{|l|}{ Marital status } \\
\hline Married & I & $<0.001$ & I & $<0.001$ \\
\hline Widowed & $1.40(0.92-2.14)$ & & $1.24(0.81-1.90)$ & \\
\hline Single, separated, or divorced & $1.28(1.15-1.41)$ & & $1.26(1.13-1.40)$ & \\
\hline Unknown & $0.98(0.74-1.29)$ & & $1.25(0.95-1.65)$ & \\
\hline \multicolumn{5}{|l|}{ AJCC stage } \\
\hline I & I & $<0.001$ & I & $<0.001$ \\
\hline ॥ & $3.95(3.02-5.16)$ & & $3.88(2.95-5.10)$ & \\
\hline III & $11.13(8.62-14.37)$ & & I I.0 (8.47-| 4.278$)$ & \\
\hline \multicolumn{5}{|l|}{ Histological type } \\
\hline Adenocarcinoma & I & $<0.001$ & I & $<0.001$ \\
\hline Mucinous adenocarcinoma & $1.39(1.22-1.59)$ & & $1.17(1.02-1.35)$ & \\
\hline Signet ring cell carcinoma & $4.52(3.55-5.76)$ & & $2.54(1.95-3.30)$ & \\
\hline \multicolumn{5}{|l|}{ Grade } \\
\hline Well differentiated & 1 & $<0.001$ & 1 & $<0.001$ \\
\hline Moderately differentiated & $\mathrm{I} .49(\mathrm{I} .2 \mathrm{I}-\mathrm{I} .83)$ & & $\mathrm{I} .14(0.93-1.4 \mathrm{I})$ & \\
\hline Poorly differentiated & $2.58(2.07-3.22)$ & & $1.47(1.17-1.85)$ & \\
\hline Undifferentiated & $3.17(2.13-4.71)$ & & $1.93(1.28-2.90)$ & \\
\hline Unknown & $1.50(1.12-2.01)$ & & $1.41(1.05-1.90)$ & \\
\hline \multicolumn{5}{|l|}{ No. of LNs examined } \\
\hline $0-11$ & 1 & $<0.001$ & I & $<0.001$ \\
\hline$\geq 12$ & $0.83(0.76-0.92)$ & & $0.71(0.64-0.79)$ & \\
\hline \multicolumn{5}{|l|}{ Year of diagnosis } \\
\hline $1990-1994$ & I & $<0.001$ & I & $<0.001$ \\
\hline $1995-1999$ & $0.79(0.69-0.91)$ & & $0.77(0.68-0.89)$ & \\
\hline 2000-2004 & $0.68(0.60-0.78)$ & & $0.69(0.61-0.80)$ & \\
\hline 2005-2009 & $0.57(0.50-0.66)$ & & $0.59(0.5 \mathrm{I}-0.68)$ & \\
\hline $2010-2014$ & $0.34(0.27-0.42)$ & & $0.35(0.28-0.45)$ & \\
\hline
\end{tabular}

Note: *Cox regression model controlling for year of diagnosis, age groups, sex, race, histological subtype, tumor grade, AJCC TNM stage, the number of LNs examined, and marriage status.

Abbreviations: HR, hazard ratio; Cl, confidence interval; RCC, right-sided colon cancer; LCC, left-sided colon cancer; AJCC, American Joint Committee on Cancer; LNs, lymph nodes.

\section{Survival analyses by tumor stage and location in age subgroups}

There were $4.9 \%$ (402 of 8197 ) 20 - to 29 -year-old, $20.8 \%$ (1703 of 8197) 30- to 39-year-old, and 74.3\% (6092 of 8197 ) 40- to 49-year-old patients. Kaplan-Meier survival curves indicated that 20- to 29 -year-old patients had the worst CSS (Figure 2A, $P=0.047$ ). However, this disparity only existed for LCCs (Figure 2C, $P=0.03$ ), not RCCs (Figure 2B, $P=0.19$ ). We separated the patients into two age subgroups, 20- to 39-year group and 40- to 49-year group, because of the small population of 20 - to 30 -yearold patients. 
A

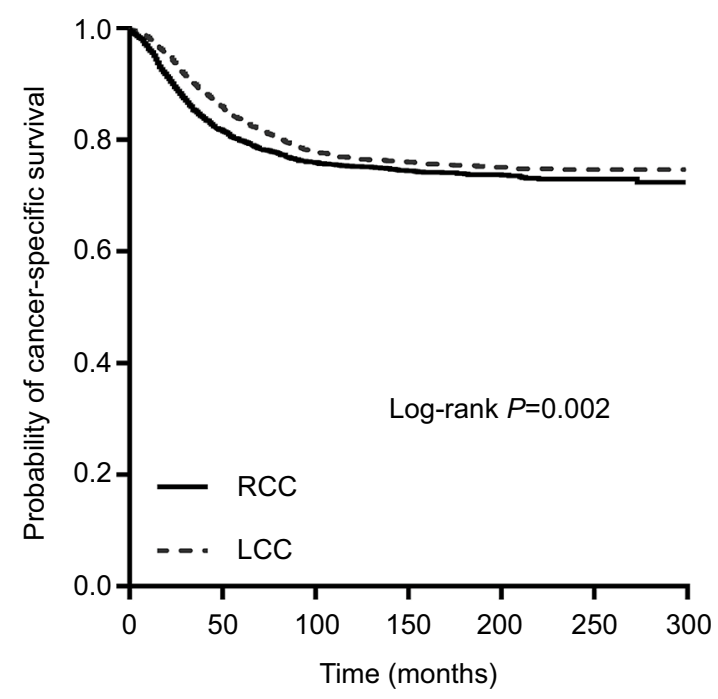

C

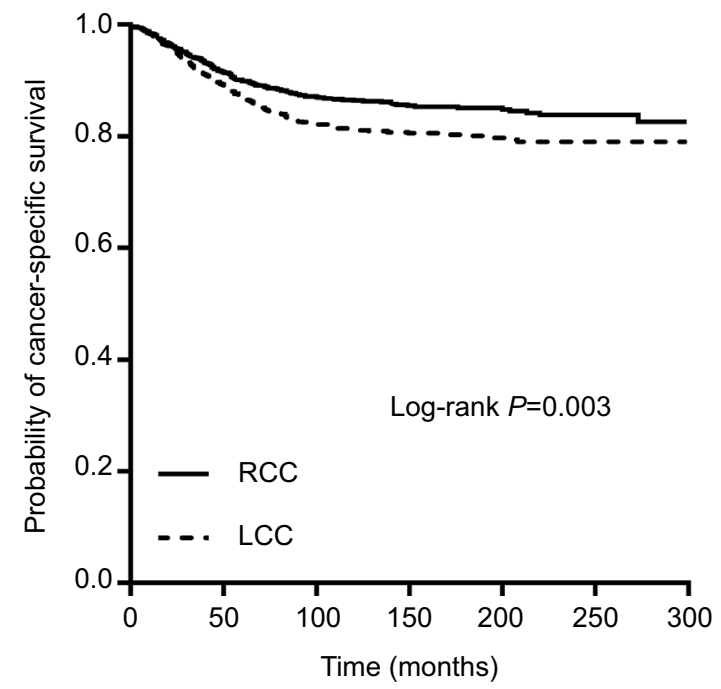

B

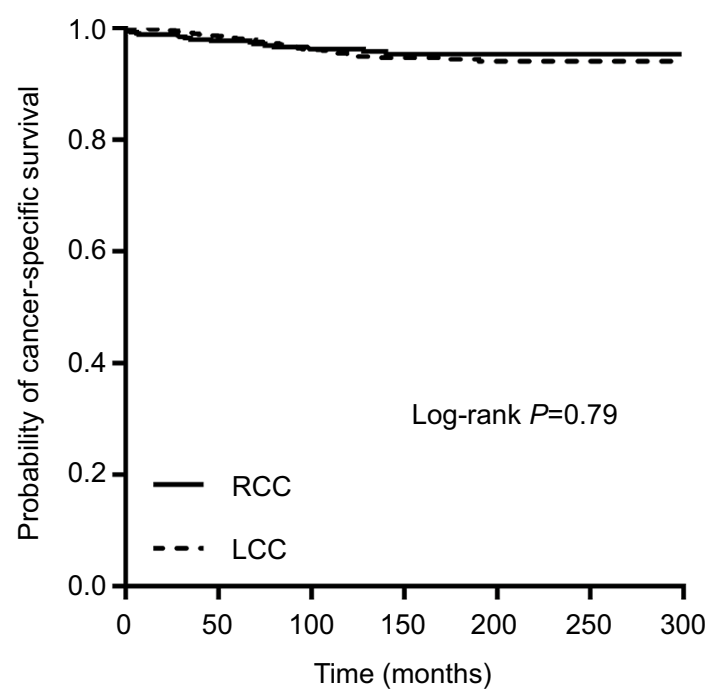

D

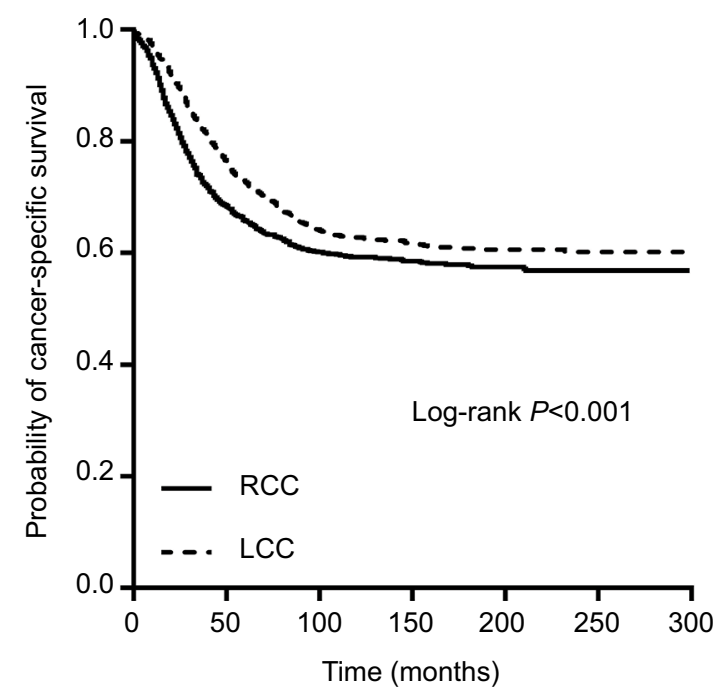

Figure I Kaplan-Meier plots of cancer-specific survival in young colon cancer patients (20-49 years old) stratified by tumor location: (A) all stages combined; (B) stage I disease; (C) stage II disease; and (D) stage III disease.

Abbreviations: RCC, right-sided colon cancer; LCC, left-sided colon cancer.

Table 4 Adjusted HRs and 95\% Cls for cancer-specific survival by stage

\begin{tabular}{|c|c|c|c|c|c|c|c|c|}
\hline \multirow{2}{*}{$\begin{array}{l}\text { Analysis } \\
\text { type }\end{array}$} & \multicolumn{2}{|c|}{ All stages $(\mathrm{N}=8197)$} & \multicolumn{2}{|c|}{ Stage I $(N=1699)$} & \multicolumn{2}{|c|}{ Stage II $(\mathrm{N}=2726)$} & \multicolumn{2}{|c|}{ Stage III $(\mathrm{N}=3772)$} \\
\hline & HR (95\% Cl) & $P$ & HR (95\% Cl) & $P$ & HR (95\% Cl) & $P$ & HR (95\% Cl) & $P$ \\
\hline \multicolumn{9}{|l|}{ Unadjusted } \\
\hline $\mathrm{RCC}$ & 1 & 0.002 & I & 0.79 & I & 0.003 & I & $<0.001$ \\
\hline LCC & $0.86(0.78-0.95)$ & & $1.08(0.62-1.86)$ & & $1.36(1.11-1.66)$ & & $0.80(0.72-0.90)$ & \\
\hline \multicolumn{9}{|l|}{ Adjusted* } \\
\hline $\mathrm{RCC}$ & 1 & 0.34 & I & 0.20 & I & 0.048 & I & 0.01 \\
\hline LCC & $0.95(0.86-1.05)$ & & $1.47(0.82-2.63)$ & & $1.24(1.00-1.54)$ & & $0.86(0.77-0.97)$ & \\
\hline
\end{tabular}

Note: *Cox regression model controlling for year of diagnosis, age groups, sex, race, histological subtype, tumor grade, AJCC TNM stage, the number of LNs examined, and marriage status.

Abbreviations: HR, hazard ratio; Cl, confidence interval; RCC, right-sided colon cancer; LCC, left-sided colon cancer; AJCC, American Joint Committee on Cancer; LNs, lymph nodes. 

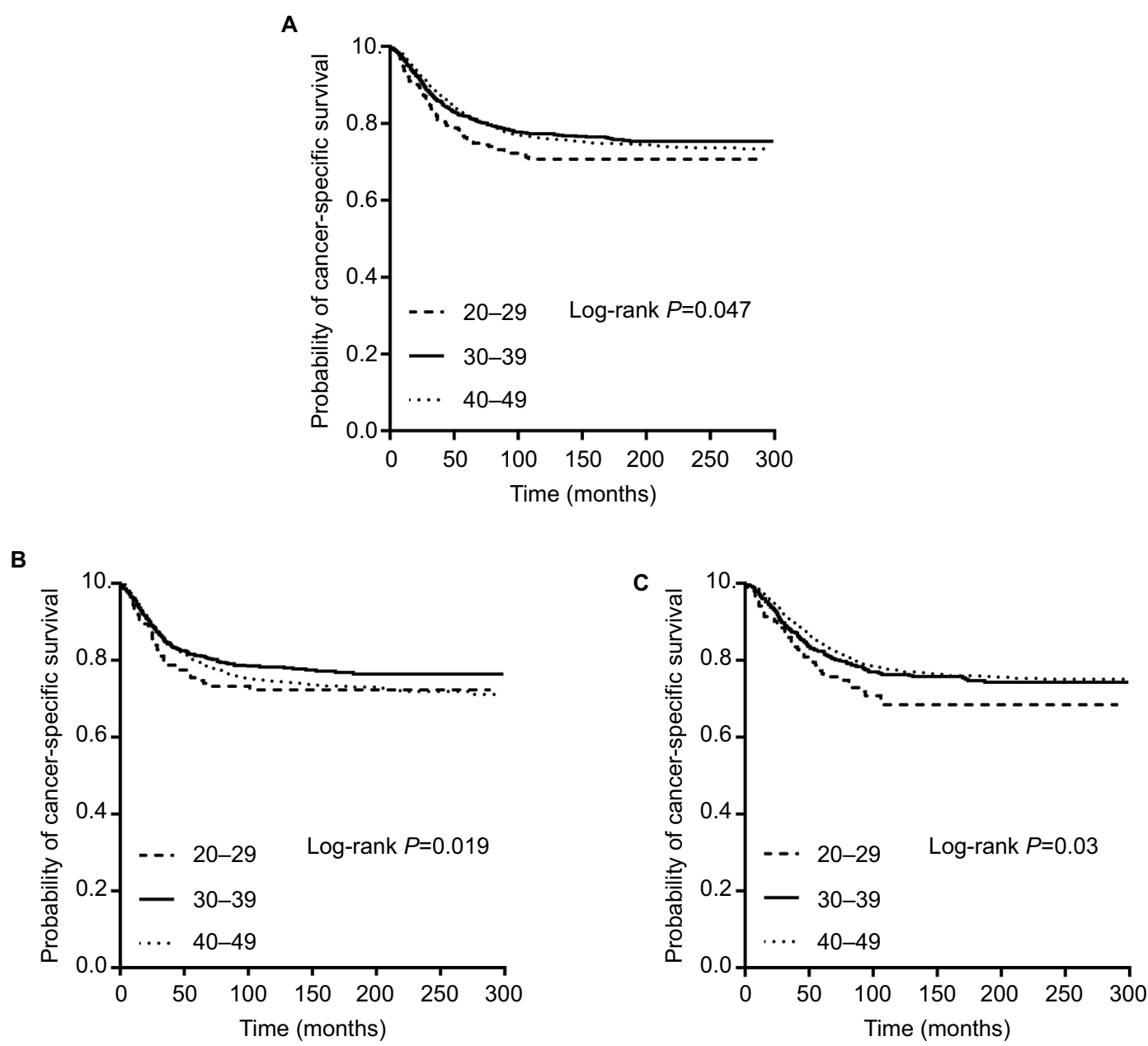

Figure 2 Kaplan-Meier plots of cancer-specific survival in young colon cancer patients (20-49 years old) stratified by age subgroups: (A) all patients; (B) right-sided colon cancers; and $(\mathbf{C})$ left-sided colon cancers.

For the 20- to 39-year-old patients, the Kaplan-Meier survival curves revealed no significant survival difference between LCCs and RCCs for all stages combined $(P=0.91)$, stage I ( $P=0.39)$, and stage III ( $P=0.17)$. However, the patients with stage II RCCs had a better CSS than did the patients with stage II LCCs $(P<0.001)$ (Figure 3A-D). Adjusted Cox survival models also revealed similar results, with no differences for all stages combined (adjusted HR, 1.12; $95 \%$ CI, 0.91-1.37; $P=0.29$ ), stage I (adjusted HR, 1.06; 95\% CI, 0.29-3.91; $P=0.92$ ), and stage III (adjusted HR, 0.99; $95 \%$ CI, 0.79-1.24; $P=0.92$ ), but a higher mortality for stage II LCCs (adjusted HR, 1.82; 95\% CI, 1.12-2.97; $P=0.02$ ) (Table 5, 20-39 years).

For the 40- to 49-year-old patients, the Kaplan-Meier survival curves revealed a decreased risk of mortality for LCCs, compared with RCCs, for all stages $(P<0.001)$ and stage III $(P<0.001)$ and no significant survival difference between LCCs and RCCs for stage I $(P=0.46)$ and stage II $(P=0.17)$ (Figure 4A-D). For stage III patients, after adjusting for the above mentioned clinicopathological features, the LCCs still had lower mortality compared with RCCs (adjusted HR, $0.83 ; 95 \% \mathrm{CI}, 0.72-0.95 ; P=0.008)$. However, the adjusted survival models revealed no difference for all stages combined (adjusted HR, 0.91; 95\% CI, 0.81-1.02; $P=0.11$ ), which was inconsistent with the results from the unadjusted models (Table $5,40-49$ years).

\section{Discussion}

Due to large-scale screening efforts, the CRC incidence in adults over the age of 50 has been declining over the past 30 years. However, CRC incidence is rising among adults younger than $50 .^{10-13} \mathrm{~A}$ SEER-based analysis with comparison to other young-onset cancers showed that CRCs were the second most incident cancers and the third leading cause of cancer deaths among adults younger than age 50 in the USA. ${ }^{14}$ This phenomenon was also verified in our study. In particular, we found a significant increase of LCCs compared with RCCs in stage III patients over the years of diagnosis 
A

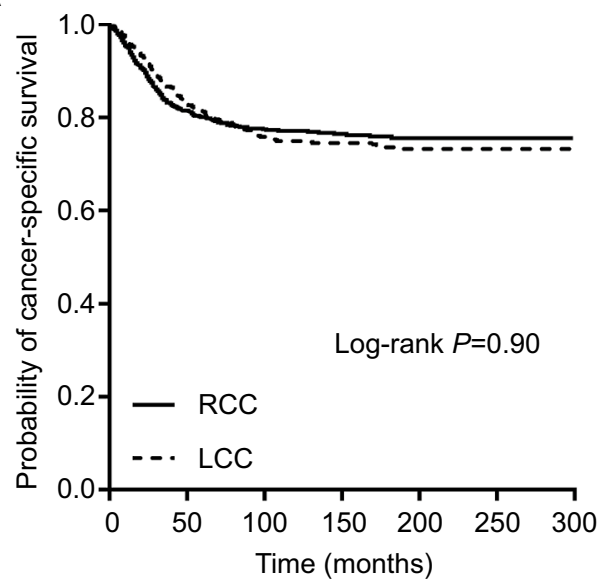

C

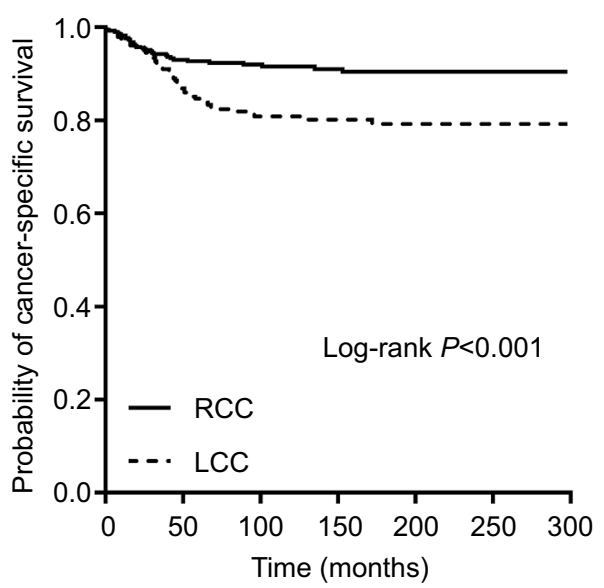

B

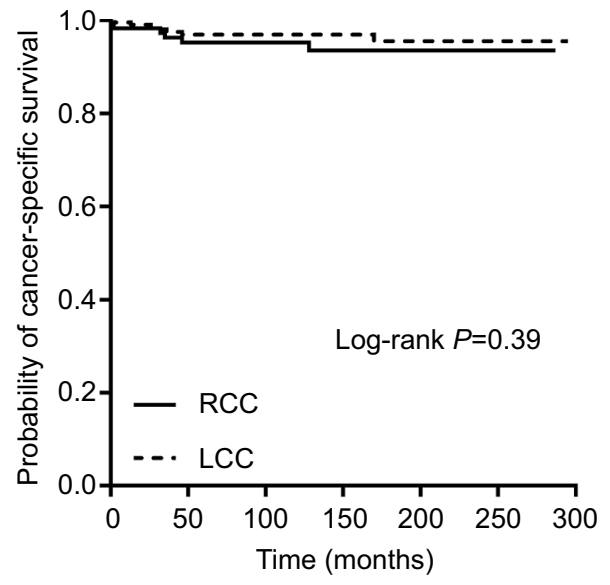

D

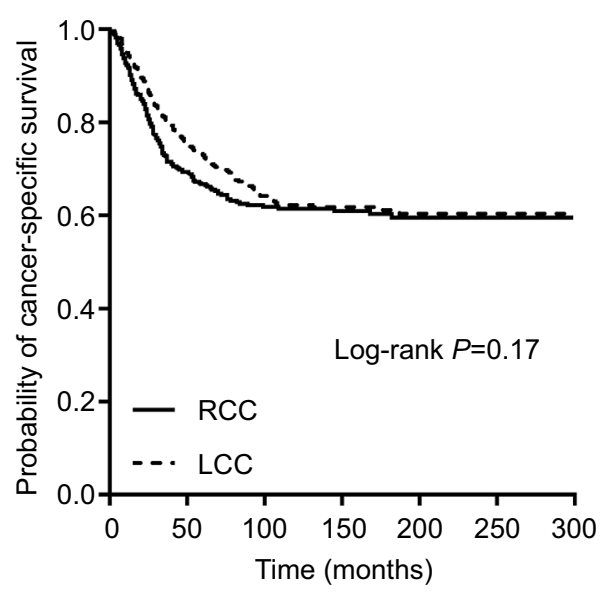

Figure 3 Kaplan-Meier plots of cancer-specific survival in young colon cancer patients (20-39 years old) stratified by tumor location: (A) all stages combined; (B) stage I disease; (C) stage II disease; and (D) stage III disease.

Abbreviations: RCC, right-sided colon cancer; LCC, left-sided colon cancer.

$(P=0.03)$, perhaps because LCCs are more easily diagnosed by colonoscopy.

CRCs in young patients are often diagnosed at a more advanced stage with more resistant and aggressive features. $^{15,16}$ Survival disparities between young and elderly patients remain controversial. Studies have supported both worse survival ${ }^{17,18}$ and better survival ${ }^{19-21}$ for young patients. In this study, we found that 20- to 29-year-old patients had the worst $\operatorname{CSS}(P=0.047)$, compared with 30- to 39-year-old and 40- to 49-year-old patients. However, this disparity only existed in LCCs $(P=0.03)$, perhaps because the very young (20-29 years old) people usually go to see a doctor and do a colonoscopy only when they have very severe symptoms and LCCs at a higher stage are more easily diagnosed.

Many previous studies have found that LCCs and RCCs are two distinct cancers with different clinicopathological features, molecular alterations, and prognoses. However, it should be noted that most of the populations in previous studies were patients older than 50 years. Those studies did not represent patients younger than 50 years. The survival differences between RCCs and LCCs among young patients are not clear. To date, this is the first study to examine whether young patients exhibit different characteristics and survival according to tumor location and stage.

It has been proposed that LCCs originate from the midgut and RCCs from the hindgut. RCCs are more likely to be exophytic and present with anemia. However, LCCs are often infiltrating lesions that present with obstructive symptoms. Patients with RCCs are more likely to be female, to be older, to be diagnosed at a more advanced stage, and to have more poorly differentiated tumors compared with LCCs. ${ }^{2}$ Similarly, in the present study, we found that RCCs in young patients also tended to be poorly differentiated and exhibited a higher frequency of stage II-III tumors. However, young patients with RCCs were more likely to be male (56.1\% [2082 of 3709 ] vs. $48.8 \%$ [2191 of 4488], $P<0.001)$ and younger 
Table 5 Adjusted HRs and 95\% Cls for cancer-specific survival by stage in different age groups

\begin{tabular}{|c|c|c|c|c|c|c|c|c|}
\hline \multirow{2}{*}{$\begin{array}{l}20-39 \text { years: } \\
\text { analysis type }\end{array}$} & \multicolumn{2}{|c|}{ All stages $(\mathrm{N}=2105)$} & \multicolumn{2}{|l|}{ Stage I $(N=336)$} & \multicolumn{2}{|c|}{ Stage II $(\mathrm{N}=702)$} & \multicolumn{2}{|c|}{ Stage III $(N=1067)$} \\
\hline & HR (95\% Cl) & $P$ & HR (95\% Cl) & $P$ & HR (95\% Cl) & $P$ & HR (95\% Cl) & $P$ \\
\hline \multicolumn{9}{|l|}{ Unadjusted } \\
\hline $\mathrm{RCC}$ & I & 0.91 & I & 0.40 & 1 & 0.001 & I & 0.17 \\
\hline LCC & I.0I (0.84-I.22) & & $0.62(0.21-1.85)$ & & $2.19(1.40-3.44)$ & & $0.86(0.70-1.07)$ & \\
\hline \multicolumn{9}{|l|}{ Adjusted* } \\
\hline $\mathrm{RCC}$ & I & 0.29 & I & 0.92 & 1 & 0.02 & 1 & 0.92 \\
\hline LCC & $1.12(0.91-1.37)$ & & $1.06(0.29-3.91)$ & & $1.82(1.12-2.97)$ & & $0.99(0.79-1.24)$ & \\
\hline \multirow{2}{*}{$\begin{array}{l}40-49 \text { years: } \\
\text { analysis type }\end{array}$} & \multicolumn{2}{|c|}{ All stages $(\mathrm{N}=6092)$} & \multicolumn{2}{|l|}{ Stage I $(N=1363)$} & \multicolumn{2}{|c|}{ Stage II $(N=2024)$} & \multicolumn{2}{|c|}{ Stage III $(\mathbf{N}=2705)$} \\
\hline & HR (95\% Cl) & $P$ & HR (95\% Cl) & $P$ & HR (95\% CI) & $P$ & HR (95\% CI) & $P$ \\
\hline \multicolumn{9}{|l|}{ Unadjusted } \\
\hline $\mathrm{RCC}$ & I & $<0.001$ & I & 0.46 & 1 & 0.17 & 1 & $<0.001$ \\
\hline LCC & $0.81(0.73-0.91)$ & & $1.277(0.67-2.45)$ & & $1.17(0.93-1.47)$ & & $0.78(0.68-0.89)$ & \\
\hline \multicolumn{9}{|l|}{ Adjusted* } \\
\hline $\mathrm{RCC}$ & I & 0.11 & I & 0.10 & 1 & 0.49 & 1 & 0.008 \\
\hline LCC & $0.91(0.81-1.02)$ & & $1.796(0.90-3.57)$ & & $1.09(0.86-1.38)$ & & $0.83(0.72-0.95)$ & \\
\hline
\end{tabular}

Note: *Cox regression model controlling for year of diagnosis, age groups, sex, race, histological subtype, tumor grade, AJCC TNM stage, the number of LNs examined, and marriage status.

Abbreviations: $\mathrm{HR}$, hazard ratio; $\mathrm{Cl}$, confidence interval; RCC, right-sided colon cancer; LCC, left-sided colon cancer; AJCC, American Joint Committee on Cancer; LNs, lymph nodes.

A

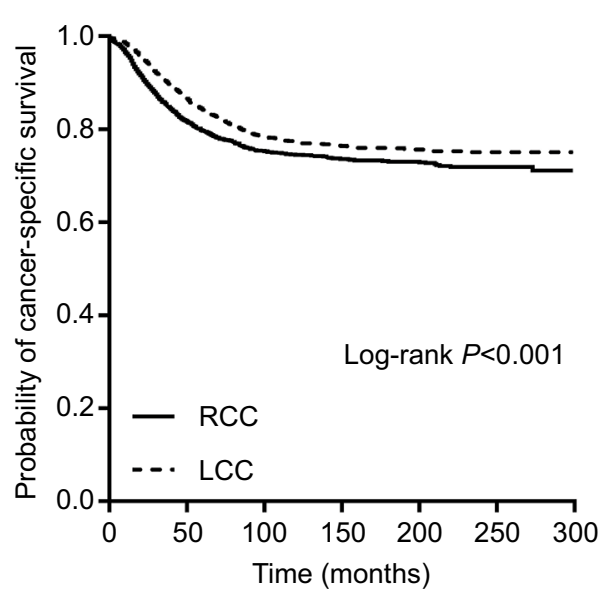

C

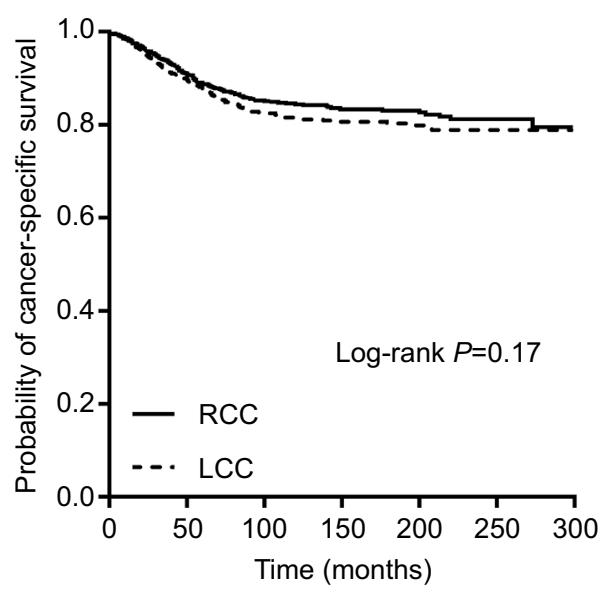

B

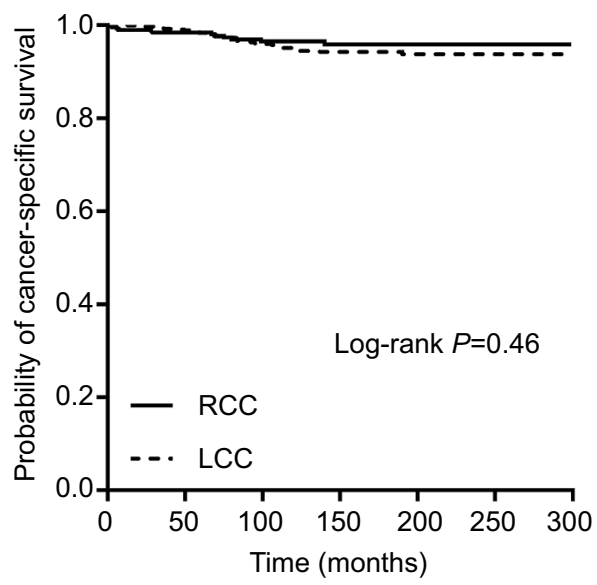

D

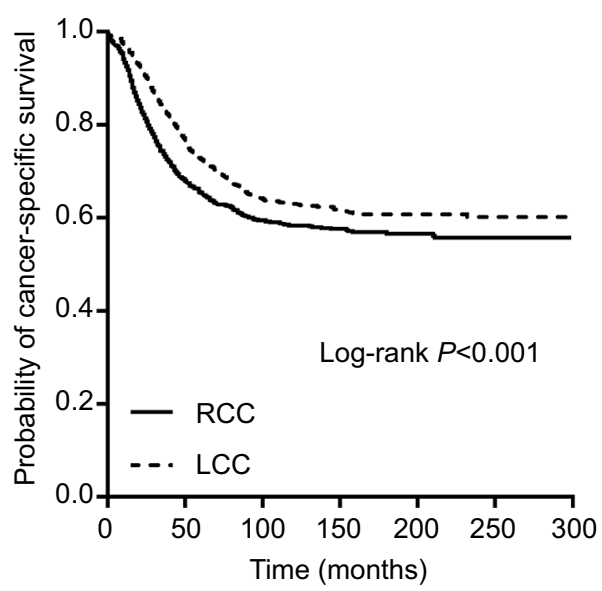

Figure 4 Kaplan-Meier plots of cancer-specific survival in young colon cancer patients (40-49 years old) stratified by tumor location: (A) all stages combined; (B) stage I disease; (C) stage II disease; and (D) stage III disease.

Abbreviations: RCC, right-sided colon cancer; LCC, left-sided colon cancer. 
(20-39 years old: $27.7 \%$ [1026 of 3709 ] vs. $24.0 \%$ [1079 of 4488], $P<0.001$ ), which were inconsistent with data in elderly patients.

In multivariate Cox models, we found that race, marital status, AJCC stage, histological type, grade, the number of LNs examined, and year of diagnosis were independent prognostic factors in all young patients. Factors including increasing AJCC stage, being mucinous or signet ring cell carcinoma, and poor differentiation were associated with increased mortality, which were easily explained by their poor clinicopathological features. Patients of Black ethnicity were related to poor prognosis compared with those of other ethnicities, probably because of their special genetic features and their poor medical treatment. The inadequate number of (0-11) LNs examined was related to higher mortality, indicating that it is important to acquire adequate number of $(\geq 12)$ LNs during the surgery of colon cancers even in young patients. Interestingly, we found that patients who were single, separated, or divorced tended to have shorter CSS, probably because of their poor income and less investment in treatment. In addition, we found a decreasing mortality over the years of diagnosis, indicating the progress in therapeutic efficacy and the good effects of large-scale screening, despite the increasing incidence during the last 30 years.

The relationship between cancer location and mortality remains controversial. Many studies have shown that patients with RCCs have shorter survival compared to those with LCCs. By analyzing the data of 77,978 cases in the SEER database (1988-2003, >18 years old, stages I-IV), Meguid et al found that the median survival for RCCs was 78 vs. 89 months for LCCs $(P<0.001) .{ }^{3}$ RCCs were associated with an increased mortality risk compared with LCCs for all stages combined (HR, 1.04; 95\% CI, 1.02-1.07), stage III (HR, 1.06 ; 95\% CI, 1.02-1.11), and stage IV (HR, 1.22; 95\% CI, 1.16-1.28). However, there were no differences in survival between patients with stage I LCCs and RCCs (HR, 1.00; 95\% CI, 0.93-1.08), and better survival was observed in patients with stage II RCCs over those with LCCs (HR, 0.91; 95\% CI, 0.88-0.95). In addition, Benedix et al found similar results by analyzing 17,641 cases in Germany (2000-2004, stages I-IV). ${ }^{4}$ Stage analysis demonstrated a significantly shorter 5-year survival rate for RCCs for all stages combined ( $67 \%$ vs. $71 \%, P<0.01)$, stage I ( $78 \%$ vs. $84 \%, P<0.01)$, and stage III ( $55 \%$ vs. $60 \%, P<0.01)$, but not for stage II (74\% vs. $72 \%$ ). In 2016, a meta-analysis of 66 studies was conducted by Petrelli et al. ${ }^{5}$ This analysis included 1,437,846 patients with a median follow-up of 65 months. LCCs were associated with a significantly reduced risk of death (HR,
0.82; 95\% CI, 0.79-0.84; $P<0.001)$. Another review and meta-analysis by Yahagi et al also advocated that patients with RCCs have significantly worse overall survival (OS) than those with LCCs. ${ }^{6}$

However, other researchers have shown that there is no significant survival difference between patients with all stages combined according to tumor location. In 2011, Weiss et al reexamined the relationship between tumor location and 5 -year mortality by analyzing 53,801 cases in the SEER database (1992-2005, >65 years old, stages I-III). ${ }^{7}$ After more extensive adjustment and limiting the sample to a more homogeneous group of patients with a narrower age distribution and a curative intent, there was no overall difference in 5-year mortality between RCCs and LCCs with all stages combined (HR, $1.01 ; 95 \% \mathrm{CI}, 0.98-1.04 ; P<0.60$ ) or for stage I cancers (HR, $0.95 ; 95 \%$ CI, $0.88-1.03 ; P<0.21$ ). However, stage II RCCs had lower mortality than LCCs (HR, 0.92; 95\% CI, 0.87-0.97; $P<0.001)$, and stage III RCCs had higher mortality (HR, 1.12; 95\% CI, 1.06-1.18; $P<0.001)$. Karim et al conducted another population-based retrospective cohort study of patients from Canada (2002-2008, stages I-III) and found that in adjusted analyses, there was no difference in long-term survival between RCCs and LCCs with all stages combined (OS: HR, 1.00; 95\% CI, 0.92-1.08 and CSS: HR, $1.00 ; 95 \%$ CI, 0.91-1.10) or for stage III disease (OS: HR, 1.03; 95\% CI, 0.93-1.14 and CSS: HR, 1.10; 95\% CI, $0.97-1.24){ }^{8}$ Interestingly, Warschkow et al analyzed 91,416 patients from the SEER database (2004-2012, stages I-III). ${ }^{22}$ After propensity score matching, the prognosis of RCCs was better than that of LCCs regarding OS and CSS for all stages combined and for stages I and II. LCCs and RCCs had similar prognoses for stage III cases.

The results of our study were similar to those reported in the study conducted by Weiss et al. ${ }^{7}$ After adjustment for multiple clinicopathological features, race, marital status, AJCC stage, histological type, grade, the number of LNs examined, and year of diagnosis were independent prognostic factors of CSS, but no significant difference in mortality was found between LCCs and RCCs for all stages combined (adjusted HR, $0.95 ; 95 \%$ CI, 0.86-1.05; $P=0.34$ ). In our study with young patients, we also found that the association between location and prognosis was not consistent across different stage groups, which was very similar to the above mentioned studies with elder patients. In adjusted Cox models, stage II LCCs had higher mortality than stage II RCCs (adjusted HR, 1.24; 95\% CI, 1.00-1.54; $P=0.048$ ) and stage III LCCs had lower mortality than stage III RCCs (adjusted HR, 0.86; $95 \% \mathrm{CI}, 0.77-0.97 ; P=0.01)$. It indicated that tumor location 
was an independent prognostic factor in stage II or stage III cancers, but the conclusions were opposite.

Furthermore, the opposite tendency of stage II and III tumors did not exist in the two age subgroups. For 20- to 39-year-old patients, a significant difference was only found in stage II disease, with a higher mortality of LCCs over RCCs (adjusted HR, 1.82; 95\% CI, 1.12-2.97; $P=0.02$ ). However, for 40- to 49-year-old patients, a significant difference was only found in stage III disease, with a lower mortality of LCCs over RCCs (adjusted HR, 0.83; 95\% CI, 0.72-0.95; $P=0.008$ ). The reasons for the different survival distribution between the two age subsets were unclear, and may be the different clinicopathological and molecular features between the two age subgroups.

The reason for better survival of young patients with stage III LCCs over those with RCCs is probably attributed to their unique clinicopathological features. In this study, young patients with RCCs were more likely to be Black people, have poorly differentiated tumor, and exhibiting higher frequencies of more advanced stages, which were all related to poor prognosis. More importantly, it is probably due to the different genetic or molecular characteristics between RCCs and LCCs.

CRCs are a group of heterogeneous diseases with multiple molecular alterations, including chromosomal instability (CIN), CpG island methylator phenotype (CIMP), gene mutations (KRAS, NRAS, BRAF, PTEN, etc.), microsatellite instability (MSI), alterations in Wnt, PI3K, TGF- $\beta$, NF- $\kappa B$ pathways, and changes of immune microenvironment. These molecular alterations play an important role in tumor formation, drug resistance, and prognosis and are considered as the basis for the individual precision treatment.

CIN exists in about $80 \%$ of CRC patients and is more common in LCCs. CIN can lead to the mutation of several tumor suppressor genes, such as APC and p53, which is an important event in the adenoma-carcinoma sequence. ${ }^{23} \mathrm{CIN}$ is reported to be an independent poor prognostic factor in colon cancers. ${ }^{24}$ The incidence of CIMP is about $15 \%$. CIMP is more common in RCCs and was related to poor prognosis in previous studies. ${ }^{25}$ In addition, it was reported that CIMP in RCCs is related to high frequencies of BRAF mutation and $\mathrm{MSI}^{26}$

EGFR-RAS-RAF-MAPK pathway is an important target in the treatment of colon cancers. Gene mutations in this pathway, such as KRAS, NRAS, BRAF, PI3KCA, and PTEN, have been of great interest in clinical cancer research. However, only KRAS mutation has been validated and is accepted in clinical practice as a predictive biomarker of response to EGFR inhibitors. Patients with KRAS-mutant tumors cannot benefit from EGFR inhibitors such as cetuximab. ${ }^{27}$ It was reported that RCCs had higher frequencies of KRAS mutations. According to the results of FIRE-3, CRYSTAL, and CALGB/SWOG 80405 clinical trials, metastatic LCCs significantly benefit more from cetuximab compared with RCCs..$^{9,28,29} \mathrm{BRAF}$ mutation exists mainly in RCCs. It is a poor prognostic factor with a higher risk of LN and peritoneal metastasis. ${ }^{30}$ Tumors with BRAF mutation also benefit less from anti-EGFR therapy. Indeed, BRAF mutation is associated with poor prognosis in microsatellite stable (MSS) and low MSI (MSI-L) CRC, but their known effect is reduced in tumors with high MSI (MSI-H) status. ${ }^{30-33}$

Compared with LCCs, RCCs have higher frequencies of CIMP, BRAF, and KRAS mutations. ${ }^{2,24}$ The above findings may explain the potential mechanism of worse survival outcome of stage III and IV RCCs in elderly colon cancer patients. Similarly, in this study, the better survival outcome of stage III LCCs in young patients may probably be explained by the above molecular alterations, although it is not yet completely clear whether there is any difference in tumor biology between elderly patients and younger patients.

The reasons for better survival of patients with stage II RCCs deserve further discussion. Weiss et al concluded that these differences were most likely related to tumor biology and especially to MSI. MSI or mismatch repair deficiency exists in $15-20 \%$ of CRC patients. MSI-H tumors are predominantly observed in RCCs and tend to be poorly differentiated. The frequency of MSI is decreased with the increase of the tumor stage, with $15-20 \%$ in stage II tumors and $<15 \%$ in stage III tumors. ${ }^{34}$ In addition, MSI-positive tumors are associated with higher degree of lymphocytic infiltration and inflammatory reaction. ${ }^{35}$ Multiple studies have found that patients with early-stage MSI-positive colon cancer have better survival. ${ }^{36-39}$ MSI-positive status is associated with a decreased risk of $\mathrm{LN}$ and distant organ metastases. ${ }^{34,40}$ PETACC-3 trial also showed better recurrence-free survival and $\mathrm{OS}$, and decreased risk of metastases, for MSI-H tumors, compared with MSI-L and MSS tumors. ${ }^{41}$ Thus, young patients with stage II RCCs may have higher rates of MSI, which probably explains the better survival of patients with stage II RCCs in this study, although few studies examined the difference of MSI status between the young patients and the elderly patients.

Our study has several limitations. First, there is currently no consensus on the definition of young CRC patients. The cutoff point in previous studies included an age of 40, 50, 
or even $45 .{ }^{42,43}$ In western countries, CRC screening is recommended for adults older than 50 . Thus, we chose age 50 as a cutoff point, but this choice might have been arbitrary. Second, some information, such as family history including Lynch syndrome and familial adenomatous polyposis, performance status, and surgical and chemotherapeutic treatments, cannot be acquired from the SEER data. It has been reported that young CRC patients tend to receive more aggressive treatments. ${ }^{44}$ These data might result in different outcomes compared with elderly patients. Third, data regarding MSI status were not available in the SEER database. Thus, we could not examine whether MSI is responsible for the better survival in stage II RCCs and whether there is any difference in MSI distribution between the young and the elderly. Forth, we cannot acquire information regarding other molecular biomarkers, such as the status of CIN, CIMP, gene mutations in EGFR-RAS-RAF-MAPK, TGF- $\beta$, NF- $\kappa$ B, PIK3CA, Wnt pathways, and so on. ${ }^{45}$ These data may explain the underlying mechanism of the disparities in prognosis as discussed above. Finally, we did not include the patients with stage IV cancers, and their targeted agents were unknown. It was reported that metastatic KRAS-wild LCCs significantly benefit more from cetuximab, and metastatic KRAS-wild RCCs relatively benefit more from bevacizumab. It is unclear whether the associations among tumor location, target agents, and survival are consistent with young patients. Recently, experts reached an agreement that described four consensus molecular subtypes (CMS) for CRCs, including CMS1 (MSI-immune), CMS2 (canonical), CMS3 (metabolic), and CMS4 (mesenchymal). It is suggested as a basis for future clinical stratification in trials and studies with potential for subtype-based targeted interventions. ${ }^{46,47}$ Further research is required to examine its applicability in young CRC patients, and there is a long way to go in the future to achieve the goal of precision treatment.

\section{Conclusion}

There was no significant difference in mortality between RCCs and LCCs for all stages combined after adjusting for multiple clinicopathological features in patients younger than 50 years old. However, this conclusion was not consistent across different stages. Adjusted models showed that RCCs had lower mortality in stage II disease (especially in 20- to 39-year-old patients) and higher mortality in stage III disease (especially in 40- to 49-year-old patients). Further research is needed to investigate the underlying mechanisms for these disparities.

\section{Acknowledgment}

This work was supported by grants from the National Natural Science Foundation of China (No. 81572955). The authors acknowledge the efforts of the Surveillance, Epidemiology, and End Results (SEER) program tumor registries in the creation of the SEER database.

\section{Disclosure}

The authors report no conflicts of interest in this work.

\section{References}

1. Siegel RL, Miller KD, Jemal A. Cancer statistics, 2017. CA Cancer J Clin. 2017;67(1):7-30.

2. Lee GH, Malietzis G, Askari A, Bernardo D, Al-Hassi HO, Clark SK. Is right-sided colon cancer different to left-sided colorectal cancer? - a systematic review. Eur J Surg Oncol. 2015;41(3):300-308.

3. Meguid RA, Slidell MB, Wolfgang CL, Chang DC, Ahuja N. Is there a difference in survival between right- versus left-sided colon cancers? Ann Surg Oncol. 2008;15(9):2388-2394.

4. Benedix F, Kube R, Meyer F, et al. Colon/Rectum Carcinomas (Primary Tumor) Study Group. Comparison of 17,641 patients with right- and left-sided colon cancer: differences in epidemiology, perioperative course, histology, and survival. Dis Colon Rectum. 2010;53(1):57-64.

5. Petrelli F, Tomasello G, Borgonovo K, et al. Prognostic survival associated with left-sided vs right-sided colon cancer: a systematic review and meta-analysis. JAMA Oncol. Epub 2016 Oct 27.

6. Yahagi M, Okabayashi K, Hasegawa H, Tsuruta M, Kitagawa Y. The worse prognosis of right-sided compared with left-sided colon cancers: a systematic review and meta-analysis. $J$ Gastrointest Surg. 2016;20(3):648-655.

7. Weiss JM, Pfau PR, O'Connor ES, et al. Mortality by stage for rightversus left-sided colon cancer: analysis of surveillance, epidemiology, and end results--Medicare data. J Clin Oncol. 2011;29(33):4401-4409.

8. Karim S, Brennan K, Nanji S, Berry SR, Booth CM. Association between prognosis and tumor laterality in early-stage colon cancer. JAMA Oncol. 2017;3(10):1386-1392.

9. Arnold D, Lueza B, Douillard JY, et al. Prognostic and predictive value of primary tumour side in patients with RAS wild-type metastatic colorectal cancer treated with chemotherapy and EGFR directed antibodies in six randomized trials. Ann Oncol. 2017;28(8):1713-1729.

10. You YN, Xing Y, Feig BW, Chang GJ, Cormier JN. Young-onset colorectal cancer: is it time to pay attention? Arch Intern Med. 2012;172(3): 287-289.

11. Ahnen DJ, Wade SW, Jones WF, et al. The increasing incidence of youngonset colorectal cancer: a call to action. Mayo Clin Proc. 2014;89(2): 216-224.

12. Edwards BK, Ward E, Kohler BA, et al. Annual report to the nation on the status of cancer, 1975-2006, featuring colorectal cancer trends and impact of interventions (risk factors, screening, and treatment) to reduce future rates. Cancer. 2010;116(3):544-573.

13. Koblinski J, Jandova J, Nfonsam V. Disparities in incidence of early- and late-onset colorectal cancer between Hispanics and Whites: a 10-year SEER database study. Am J Surg. 2018;215(4):581-585.

14. Bhandari A, Woodhouse M, Gupta S. Colorectal cancer is a leading cause of cancer incidence and mortality among adults younger than 50 years in the USA: a SEER-based analysis with comparison to other young-onset cancers. J Investig Med. 2017;65(2):311-315.

15. Myers EA, Feingold DL, Forde KA, Arnell T, Jang JH, Whelan RL. Colorectal cancer in patients under 50 years of age: a retrospective analysis of two institutions' experience. World $J$ Gastroenterol. 2013;19(34):5651-5657. 
16. Ballester V, Rashtak S, Boardman L. Clinical and molecular features of young-onset colorectal cancer. World J Gastroenterol. 2016;22(5): 1736-1744.

17. Chan KK, Dassanayake B, Deen R, et al. Young patients with colorectal cancer have poor survival in the first twenty months after operation and predictable survival in the medium and long-term: analysis of survival and prognostic markers. World J Surg Oncol. 2010;8:82.

18. Zhao L, Bao F, Yan J, et al. Poor prognosis of young patients with colorectal cancer: a retrospective study. Int $J$ Colorectal Dis. 2017;32(8):1147-1156.

19. Li M, Li JY, Zhao AL, Gu J. Do young patients with colorectal cancer have a poorer prognosis than old patients? J Surg Res. 2011;167(2): 231-236.

20. Yeo SA, Chew MH, Koh PK, Tang CL. Young colorectal carcinoma patients do not have a poorer prognosis: a comparative review of 2,426 cases. Tech Coloproctol. 2013;17(6):653-661.

21. Wang R, Wang MJ, Ping J. Clinicopathological features and survival outcomes of colorectal cancer in young versus elderly: a populationbased cohort study of SEER 9 registries data (1988-2011). Medicine (Baltimore). 2015;94(35):e1402.

22. Warschkow R, Sulz MC, Marti L, et al. Better survival in right-sided versus left-sided stage I - III colon cancer patients. BMC Cancer. 2016;16:554

23. Fearon ER, Vogelstein B. A genetic model for colorectal tumorigenesis. Cell. 1990;61(5):759-767.

24. Shen H, Yang J, Huang Q, et al. Different treatment strategies and molecular features between right-sided and left-sided colon cancers. World J Gastroenterol. 2015;21(21):6470-6478.

25. Juo YY, Johnston FM, Zhang DY, et al. Prognostic value of CpG island methylator phenotype among colorectal cancer patients: a systematic review and meta-analysis. Ann Oncol. 2014;25(12):2314-2327.

26. Vedeld HM, Merok M, Jeanmougin M, et al. CpG island methylator phenotype identifies high risk patients among microsatellite stable BRAF mutated colorectal cancers. Int J Cancer. 2017;141(5):967-976.

27. De Roock W, Jonker DJ, Di Nicolantonio F, et al. Association of KRAS p.G13D mutation with outcome in patients with chemotherapyrefractory metastatic colorectal cancer treated with cetuximab. JAMA. 2010;304(16):1812-1820.

28. Heinemann V, von Weikersthal LF, Decker T, et al. FOLFIRI plus cetuximab versus FOLFIRI plus bevacizumab as first-line treatment for patients with metastatic colorectal cancer (FIRE-3): a randomised, open-label, phase 3 trial. Lancet Oncol. 2014;15(10):1065-1075.

29. Tejpar S, Stintzing S, Ciardiello F, et al. Prognostic and predictive relevance of primary tumor location in patients with RAS wild-type metastatic colorectal cancer: retrospective analyses of the CRYSTAL and FIRE-3 trials. JAMA Oncol. Epub 2016 Oct 10.

30. Roth AD, Tejpar S, Delorenzi M, et al. Prognostic role of KRAS and BRAF in stage II and III resected colon cancer: results of the translational study on the PETACC-3, EORTC 40993, SAKK 60-00 trial. $J$ Clin Oncol. 2010;28(3):466-474.

31. Pai RK, Jayachandran P, Koong AC, et al. BRAF-mutated, microsatellitestable adenocarcinoma of the proximal colon: an aggressive adenocarcinoma with poor survival, mucinous differentiation, and adverse morphologic features. Am J Surg Pathol. 2012;36(5):744-752.
32. Ogino S, Shima K, Meyerhardt JA, et al. Predictive and prognostic roles of BRAF mutation in stage III colon cancer: results from intergroup trial CALGB 89803. Clin Cancer Res. 2012;18(3):890-900.

33. de Cuba EM, Snaebjornsson P, Heideman DA, et al. Prognostic value of BRAF and KRAS mutation status in stage II and III microsatellite instable colon cancers. Int J Cancer. 2016;138(5):1139-1145.

34. Jernvall P, Makinen MJ, Karttunen TJ, Makela J, Vihko P. Microsatellite instability: impact on cancer progression in proximal and distal colorectal cancers. Eur J Cancer. 1999;35(2):197-201.

35. De Smedt L, Lemahieu J, Palmans S, et al. Microsatellite instable vs stable colon carcinomas: analysis of tumour heterogeneity, inflammation and angiogenesis. Br J Cancer. 2015;113(3):500-509.

36. Ribic CM, Sargent DJ, Moore MJ, et al. Tumor microsatellite-instability status as a predictor of benefit from fluorouracil-based adjuvant chemotherapy for colon cancer. N Engl J Med. 2003;349(3):247-257.

37. Popat S, Hubner R, Houlston RS. Systematic review of microsatellite instability and colorectal cancer prognosis. J Clin Oncol. 2005;23(3):609-618.

38. Hemminki A, Mecklin JP, Jarvinen H, Aaltonen LA, Joensuu H. Microsatellite instability is a favorable prognostic indicator in patients with colorectal cancer receiving chemotherapy. Gastroenterology. 2000;119(4):921-928.

39. Samowitz WS, Curtin K, Ma KN, et al. Microsatellite instability in sporadic colon cancer is associated with an improved prognosis at the population level. Cancer Epidemiol Biomarkers Prev. 2001;10(9):917-923.

40. Malesci A, Laghi L, Bianchi P, et al. Reduced likelihood of metastases in patients with microsatellite-unstable colorectal cancer. Clin Cancer Res. 2007;13(13):3831-3839.

41. Klingbiel D, Saridaki Z, Roth AD, Bosman FT, Delorenzi M, Tejpar S. Prognosis of stage II and III colon cancer treated with adjuvant 5-fluorouracil or FOLFIRI in relation to microsatellite status: results of the PETACC-3 trial. Ann Oncol. 2015;26(1):126-132.

42. O'Connell JB, Maggard MA, Livingston EH, Yo CK. Colorectal cancer in the young. Am J Surg. 2004;187(3):343-348.

43. Levin B, Lieberman DA, McFarland B, et al; American Cancer Society Colorectal Cancer Advisory Group; US Multi-Society Task Force; American College of Radiology Colon Cancer Committee. Screening and surveillance for the early detection of colorectal cancer and adenomatous polyps, 2008: a joint guideline from the American Cancer Society, the US Multi-Society Task Force on Colorectal Cancer, and the American College of Radiology. CA Cancer J Clin. 2008;58(3): $130-160$.

44. Rho YS, Gilabert M, Polom K, et al. Comparing clinical characteristics and outcomes of young-onset and late-onset colorectal cancer: an International Collaborative study. Clin Colorectal Cancer. 2017;16(4):334-342.

45. De Rosa M, Rega D, Costabile V, et al. The biological complexity of colorectal cancer: insights into biomarkers for early detection and personalized care. Therap Adv Gastroenterol. 2016;9(6):861-886.

46. Muller MF, Ibrahim AE, Arends MJ. Molecular pathological classification of colorectal cancer. Virchows Arch. 2016;469(2):125-134.

47. Lee MS, Menter DG, Kopetz S. Right versus left colon cancer biology: integrating the consensus molecular subtypes. J Natl Compr Canc Netw. 2017;15(3):411-419.
Cancer Management and Research

\section{Publish your work in this journal}

Cancer Management and Research is an international, peer-reviewed open access journal focusing on cancer research and the optimal use of preventative and integrated treatment interventions to achieve improved outcomes, enhanced survival and quality of life for the cancer patient. The manuscript management system is completely online and includes

\section{Dovepress}

a very quick and fair peer-review system, which is all easy to use. Visit http://www.dovepress.com/testimonials.php to read real quotes from published authors. 